\title{
VALORES HEMATIMÉTRICOS NORMAIS EM SUÍNOS Sus scrofa dom. LINEU, 1758, DAS RAÇAS LANDRACE E LARGE WHITE NO PARANÁ, BRASIL
}

\author{
Hematimetrical Normal Values in Sus Scrofa dom. Lineu, 1758 \\ Swines, of Races Landrace and Large White in Parana, Brazil
}

Antônia Maria do Rocio Binder do Prado ${ }^{1}$

\section{Resumo}

Com a finalidade de contribuir para o conhecimento de valores hematimétricos normais em suínos criados no estado do Paraná, foram utilizados 100 animais adultos com idade entre 8 e 12 meses, das raças Landrace e Large White, provenientes do município de São José dos Pinhais, no Estado do Paraná - Brasil. Para cada raça estudada, foram utilizados 50 suínos, sendo 25 machos castrados e 25 fêmeas. Os animais estudados foram criados em regime de confinamento, alimentados com ração preparada no próprio local e suplementada, em relação aos machos, com verduras e legumes e, em relação às fêmeas, com milho, farelo e concentrado. As misturas formm pasteurizadas. Além da ração, os animais recebiam ad libitum, uma mistura comercial contendo farinha de ostra, macro e microelementos. Os exames hematimétricos foram realizados eletronicamente, utilizando-se um aparelho de fabricação Coulter Electronic - modelo D2, com diluidor Coulter Dual Diluter - III. Os dados estatísticos referem-se a 17 variáveis e foram analisados segundo um delineamento experimental inteiramente casualizado, com os tratamentos arranjados fatorialmente. Não houve diferenças entre as médias para os sexos e para as raças, em relação às variáveis eritrócitos e basófilos. Os fatores raça e sexo são independentes, existindo diferenças estatisticamente significativas, a $95 \%$ de probabilidade, entre sexos, para as variáveis número de leucócitos, eosinófilos, linfócitos, hemoglobina, volume globular e volume corpuscular médio.

Palavras-chave: Células sangüíneas; Hemograma.

\footnotetext{
${ }^{1}$ Prof. Titular da PUCPR, Av. 7 de Setembro, 4699, ap. 1601, Batel, Curitiba, PR, CEP 80.240-000, E-mail:prado@rla01.pucpr.br.
} 


\section{Abstract}

With the purpose to contribute for the knowledge of normal hematimetrical values in swines produced in Parana State, a group of 100 adult animals with age between 8 and 12 month was used, of the Landrace and Large White races, from Municipality of São José dos Pinhais, in the state of Parana - Brazil. For each studied race 50 swines had been used, being 25 castrated males and 25 females. The studied animals had been created confined, fed with locally prepared ration and supplemented, for the males with greens and vegetables and, in for the females, with maize, bran and concentrate. The mixtures were submitted to a pasteurization. Complementary to the ration, the animals received ad libitum a commercial mixture contend with oyster flour, macro and microelements. The hematimetrical examinations had been carried out using an electronic device, manufactured by Coulter Electronic - model $\mathrm{D}_{2}$, with Coulter Dual Diluter-III. The statistical data of 17 variables had been analyzed according to a complete random experimental design, with factorial arrangement of the treatments. It was observed that differences between the averages do not exist, even for the sexes, other for the races in relation to the variables erythrocites and basophiles. The factors race and sex are independent, existing significant statistical differences, at 95\% probability level, between sexes for the variables number of leukocites, eosinophiles, lymphocites, hemoglobin, globular volume and average corpuscular volume.

Keywords: Blood cells; Hemogram.

\section{Introdução}

A suinocultura representa uma faceta de apreciável evidência na economia agropecuánia, principalmente no Estado do Paraná. É notório que nos últimos anos houve convergência de esforços das entidades governamentais e particulares, no sentido de conferir melhores caracteństicas zootécnicas às raças criadas na região, mediante fomento. Pesquisas acenca de profilaxia das moléstias parasitárias e contagiosas são necessárias para o melhoramento zootécnico, porém essas não têm sido realizadas no Brasil, conquanto outros aspectos do controle zootécnico tenham sido efetuados.

Esse trabalho visa a contribuir para a ampliação de informações de interesse científico e ter um direcionamento prático no âmbito da patologia, relativo ao diagnóstico das moléstias que acometem os suínos. Assim, foram investigados os valores hematimétricos normais de duas raças de suínos, Landrace e Large White, representativas do rebanho suíno do Estado do Paraná, pois existe interesse no estudo da fisiopatologia, devido à grande variabilidade desses valores em suínos, geral- mente decorrente dos fatores raça, sexo, idade, clima, altitude e estação do ano. Deve-se salientar a carência de informações relativas aos valores hematimétricos normais em suínos na literatura especializada no Brasil, inexistentes no Estado do Paraná, logo, esse trabalho visa a contribuir para 0 esclarecimento de padrões hematimétricos mais seguros e, assim, servir de apoio para o diagnóstico clínico-laboratorial das entidades mórbidas que aparentem acometer os suínos.

\section{Material e métodos}

Foi coletado sangue de 100 suínos adultos, variando de 8 meses a 1 ano de idade, das raças Large White e Landrace, onde 25 eram machos castrados e 25 eram fêmeas, de cada raça. Os suínos pertenciam à fazenda Wast Farm, localizada no município de São José dos Pinhais, Paraná, a uma altitude média de 910,2 metros. Os dados meteorológicos relativos a esse município, captados pelo Destacamento de Proteção de Vôo do Ministério da Aeronáutica - Estação, constam na Tabela 1.

\section{Tabela 1 - Dados meteorológicos do município de São Jose dos Pinhais, Paraná, Brasil, refe- rentes ao mês de janeiro de 1985.}

Table 1 - Weather data of the city of São José dos Pinhais, Paraná, Brazil, referring to January 1985.

\begin{tabular}{|ll|}
\hline Temperatura media (C) & 19,7 \\
\hline Umidade relativa do ar (\%) & 81 \\
\hline Precipitação pluviométrica (mm \#) & 62,25 \\
\hline
\end{tabular}


Os suínos das duas raças mencionadas, utilizados para o presente estudo, foram criados em regime de confinamento, alimentados com ração preparada no próprio local e suplementada, em relação aos machos, com verdura e legumes; em relação às fêmeas, com milho, farelo e concentrado. As misturas foram submetidas à pasteurização. Além da ração, os animais recebiam, ad libitum, uma mistura comercial contendo farinha de ostra, macro e microelementos. Os animais recebiam ainda o vegetal confrei (Symphytum officinalis), na quantidade de 0,5 kg, aproximadamente, por cabeça, diariamente. Os suínos foram distribuídos em lotes de 12 a 14 animais e mantidos em pocilgas com piso de cimento, com $0,8 \mathrm{~m}^{2} \mathrm{de}$ área por cabeça.

Foi observada uma divisão dos animais em relação à idade, época de reprodução, desmame e engorda. Deve-se acrescentar que os suínos utilizados para o presente estudo eram rotineiramente desverminados com o anti-helmíntico cloridrato de tetramissol. Cerca de 22 dias antes da coleta de material os animais receberam uma dose do vermífugo.

Uma amostra aleatória, com 20 animais (10 machos e 10 fêmeas) foi tomada dos 100 suínos, para realizar o exame ovo-helmintoscópico das fezes, visando a estimar a incidência de parasitas gastrointestinais, tendo o material sido colhido da ampola retal. Foi utilizada a técnica descrita inicialmente por Gordon; Witlock (1939-1940), baseada no princípio de diluição e levitação. Os animais das duas raças estudadas apresentaram infestação subclínica ou não apresentaram vermes. O sangue foi obtido na quantidade de $5 \mathrm{ml}$ por incisão da veia marginal da orelha, utilizando-se uma lâmina de bisturi e armazenado em frascos previamente numerados, que continham uma gota de solução a 5\% de EDTA (ácido etileno-diaminotetracético, sal dipotássico), ou seja, 2,5 mg de sal para o total do sangue colhido.

Na ocasião da coleta de sangue realizaram-se esfregaços com gota de sangue proveniente diretamente da incisão superficial, tomando-se 0 cuidado de desprezar as primeiras gotas. As amostras eram levadas ao laboratório no prazo máximo de 2 horas após a coleta. Para as análises, utilizou-se um aparelho eletrônico conta-glóbulos de fabricação da Coulter Dual Diluter III. Fez-se a contagem do número global de eritrócitos e do número global de leucócitos, a determinação do volume globular e a dosagem de hemoglobina. Os valores dos índices hematimétricos corpusculares representados pelo volume corpuscular médio (VCM), hemoglobina corpuscular média (HCM) e concentração de hemoglobina corpuscular média (CHCM) foram calculados em conformidade com o proposto por Wintrobe (1929).

Contou-se em média 200 leucócitos, 50 em cada uma das quatro zonas diferentes do esfregaço, para as determinações diferenciais. Os esfregaços foram corados com uma associação seqüencial, conforme os métodos de coloração hematológica de Leishman e Giemsa, segundo FREITAS (1967).

\section{Delineamento estatístico}

Os dados foram analisados segundo um delineamento inteiramente casualizado, com quatro tratamentos e arranjados fatorialmente, com 25 repetições cada. Testaram-se dois fatores: sexo e raça , cada um com duas situações em relação às raças estudadas.

Após a análise de variância, as médias foram comparadas pelo teste de Tukey, ao nível de 95\% de probabilidade. Quando as interações não foram testadas, atinha-se às médias dos fatores para cada uma das situações.

As análises foram feitas utilizando-se o pacote estatístico S.P.S.S.(Statistical Package for the Social Sciences), no Centro de Computação da Universidade Federal do Paraná, em equipamento Digital-Equipament Cooperation (Dec-lO System).

\section{Resultados e discussão}

Os resultados da pesquisa efetuada estão apresentados nas Tabelas 19 a 20, em que se anotaram a discriminação dos animais estudados, 0 sexo, a raça, os valores encontrados nos exames de sangue (série branca e série vermelha) e suas médias aritméticas e os extremos máximo e mínimo. Os resultados estatísticos encontram-se em tabelas que acompanham a análise dos diferentes aspectos dos elementos estudados (TABELAS de 2 a 17). 


\section{Eritrócitos}

Tabela 2 - Comparação das medias em eritrócitos (milhões / $\mathrm{mm}^{3}$, pelo teste de Tukey, ao nível de $95 \%$ de probabilidade).

Table 2 - Comparison of the averages in erythrocites (millions/mm_), using Tukey test with $95 \%$ of probability.

\begin{tabular}{|lll|}
\hline & LANDRACE & LARGE WHITE \\
\hline Machos & 6,714 Aa & $6,668 \mathrm{Aa}$ \\
\hline Fêmeas & $6,903 \mathrm{Aa}$ & $7,051 \mathrm{Aa}$ \\
\hline MÉDIA GERAL & 6,834 milhões & por mm_de sangue \\
\hline
\end{tabular}

Não houve diferença significativa entre as médias de eritrócitos (milhões/ $\mathrm{mm}^{3}$ ) das raças dentro de cada categoria (macho e fêmea) e das categorias dentro de cada raça.

Observações: Médias seguidas pela mesma letra maiúscula não diferem estatisticamente pelo teste de Tukey ao nível de 95\% de probabilidade, quando consideradas as raças dentro de cada categoria (sentido horizontal). Médias seguidas pela mesma letra minúscula não diferem estatisticamente pelo teste de Tukey ao nível de $95 \%$ de probabilidade, quando consideradas as categorias dentro de cada raça (sentido vertical).

\section{Hemoglobina}

Tabela 3 - Comparação das médias para o teor de hemoglobina (g), pelo teste de Tukey ao nível de $5 \%$ de probabilidade.

Table 3 - Comparison of the averages for the hemoglobin text (g), using Tukey test with 95\% of probability.

\begin{tabular}{|c|c|c|}
\hline & LANDRACE & LARGE WHITE \\
\hline Machos & $10.88 \mathrm{Aa}$ & $11,06 \mathrm{Aa}$ \\
\hline Fêmeas & $12,26 \mathrm{Ab}$ & $12,30 \mathrm{Ab}$ \\
\hline MÉDIA GERAL & 11,62 milhões & $00 \mathrm{~mm}$ de sangue \\
\hline
\end{tabular}

Não houve diferença significativa entre as médias do teor de hemoglobina (g) das raças e sexo, porém houve entre os sexos.

Observações: As mesmas da tabela 2. 


\section{Volume globular}

Tabela 4 - Comparação das médias do volume globular (\%), pelo teste de Tukey ao nível de 95\% de probabilidade.

Table 4 - Comparison of the averages of the globular volume (\%), using Tukey test with 95\% of probability.

\begin{tabular}{|lll|}
\hline & LANDRACE & LARGE WHITE \\
\hline Machos & $36.84 \mathrm{Aa}$ & $35,76 \mathrm{Aa}$ \\
\hline Fêmeas & $39.76 \mathrm{Aa}$ & $39.96 \mathrm{Ab}$ \\
\hline MÉDIA GERAL & 11,62 milhões por $100 \mathrm{~mm}$ de sangue \\
\hline
\end{tabular}

Não houve diferença significativa entre as médias do volume globular (\%) das raças, porém existiu entre os sexos.

Observações: As mesmas da tabela 2.

\section{Volume corpuscular Médio (VCM)}

Tabela 5 - Comparação das médias do volume corpuscular médio (um ), pelo teste de Tukey ao nível de $5 \%$ de probabilidade

Table 5 - Comparison of the averages of corpuscular volume ( $\mathrm{m}_{-}$), using Tukey test with $95 \%$ of probability.

\begin{tabular}{|lll|}
\hline & LANDRACE & LARGE WHITE \\
\hline Machos & $55.21 \mathrm{Aa}$ & $53.80 \mathrm{Aa}$ \\
\hline Fêmeas & $58.30 \mathrm{Ab}$ & $57.24 \mathrm{Ab}$ \\
\hline MÉDIA GERAL & 56.14 milímetros cúbicos \\
\hline
\end{tabular}

Houve diferença significativa entre as médias do volume corpuscular médio ( m3) entre os sexos para cada raça e não houve entre as raças para os sexos.

Observações: As mesmas da tabela 2. 


\section{Hemoglobina corpuscular média (HCM)}

(uug)

Tabela 6 - Comparação das médias de hemoglobina corpuscular média (uug), pelo teste de Tukey ao nível de $95 \%$ de probabilidade

Table 6 - Comparison of the averages of corpuscular hemoglobin ( g), using Tukey test with 95\% of probability.

\begin{tabular}{|lll|}
\hline & LANDRACE & LARGE WHITE \\
\hline Machos & $16,57 \mathrm{Aa}$ & $16.34 \mathrm{Aa}$ \\
\hline Fêmeas & $18,04 \mathrm{Ab}$ & $17.41 \mathrm{Ab}$ \\
\hline MÉDIA GERAL & 17.00 milímetros cúbicos \\
\hline
\end{tabular}

Houve diferença significativa entre as médias de hemoglobina corpuscular média ( $g$ ) dos sexos e não das raças.

Observações: As mesmas da tabela 2.

\section{Hemoglobina corpuscular média (HCM)}

( uug)

Tabela 7 - Comparação das médias de hemoglobina corpuscular média (\%), pelo teste de Tukey ao nível de $95 \%$ de probabilidade

Table 7 - Comparison of averages of corpuscular hemoglobin (\%), using Tukey test with 95\% of probability

\begin{tabular}{|lll|}
\hline & LANDRACE & LARGE WHITE \\
\hline Machos & $30.09 \mathrm{Aa}$ & $30.43 \mathrm{Aa}$ \\
\hline Fêmeas & $30.98 \mathrm{Ab}$ & $30.46 \mathrm{Ab}$ \\
\hline MÉDIA GERAL & $30.49 \%$ & \\
\hline
\end{tabular}

Houve diferença significativa entre as médias de hemoglobina corpuscular média (\%) da raça Landrace e não entre as da Large White. Não houve diferença entre as médias dos sexos em ambas as raças.

Observações: As mesmas da tabela 2.

\section{Leucócitos}

Tabela 8 - Comparação das médias das porcentagens de leucócitos no sangue=mm3 pelo teste de Tukey ao nível de $95 \%$ de probabilidade.

Table 8 - Comparison of the averages of leukocytes in blood ( $\mathrm{mm}$ ), using Tukey test with 95\% of probability.

\begin{tabular}{|lll|}
\hline & LANDRACE & LARGE WHITE \\
\hline Machos & $21.260 \mathrm{Aa}$ & $20.240 \mathrm{Aa}$ \\
\hline Fêmeas & $18.624 \mathrm{Aa}$ & $17.064 \mathrm{Aa}$ \\
\hline MÉDIA GERAL & $19.624 \mathrm{Ab}$ & \\
\hline
\end{tabular}

Houve diferença significativa entre as médias de percentagens de leucócitos no sangue $\left(\mathrm{mm}^{3}\right)$ entre os sexos e não entre as raças.

Observações: As mesmas da tabela 2. 


\section{Neutrófilos (\%)}

Tabela 9 - Comparação das médias das porcentagens de neutrófilos (\%) pelo teste de Tukey ao nível de $95 \%$ de probabilidade.

Table 9 - Comparison of the averages of neutrophiles (\%), using Tukey test with 95\% of probability.

\begin{tabular}{|lll|}
\hline & LANDRACE & LARGE WHITE \\
\hline Machos & $31.64 \mathrm{Aa}$ & $30.48 \mathrm{Aa}$ \\
\hline Fêmeas & $30.28 \mathrm{Aa}$ & $27.40 \mathrm{Aa}$ \\
\hline MÉDIA GERAL & 29.95 por cento & \\
\hline
\end{tabular}

Não houve diferença significativa entre as médias das percentagens de neutrófilos (\%) entre as raças e entre os sexos.

Observações: As mesmas da tabela 2.

\section{Neutrófilos $\left(/ \mathrm{mm}^{3}\right)$}

Tabela 10. Comparação das médias das porcentagens de neutrófilos $\left(\mathrm{mm}^{3}\right)$ pelo teste de Tukey ao nível de $5 \%$ de probabilidade

Table 10 - Comparison of the averages of neutrophiles (mm_), using Tukey test with $95 \%$ of probability

\begin{tabular}{|lll|}
\hline & LANDRACE & LARGE WHITE \\
\hline Machos & $6.835,92 \mathrm{Aa}$ & $6.448,60 \mathrm{Ba}$ \\
\hline Fêmeas & $5.658,84 \mathrm{Ab}$ & $4.575,20 \mathrm{Bb}$ \\
\hline MÉDIA GERAL & $5.854,64$ por m- & \\
\hline
\end{tabular}

Houve diferença significativa entre as médias de percentagens de neutrófilos $\left(\mathrm{mm}^{3}\right)$ entre as raças e entre os sexos.

Observações: As mesmas da tabela 2.

\section{Eosinófilos (\%)}

Tabela 11 - Comparação das médias das porcentagens de eosinófilos (\%) pelo teste de Tukey ao nível de $95 \%$ de probabilidade.

Table 11 - Comparison of the averages of eosinophiles (\%), using Tukey test with 95\% of probability.

\begin{tabular}{|lll|}
\hline & LANDRACE & LARGE WHITE \\
\hline Machos & $2.60 \mathrm{Ab}$ & $2.56 \mathrm{Ab}$ \\
\hline Fêmeas & $5.16 \mathrm{Aa}$ & $5.12 \mathrm{Aa}$ \\
\hline MÉDIA GERAL & 3.86 por cento & \\
\hline
\end{tabular}

entre os sexos.

Houve diferença significativa entre as médias de percentagens de eosinófilos (\%) entre as raças e

Observações: As mesmas da tabela 2. 


\section{Eosinófilos $\left(/ \mathrm{mm}^{3}\right)$}

Tabela 12 - Comparação das médias das porcentagens de eosinófilos (\%) pelo teste de Tukey ao nível de $95 \%$ de probabilidade.

Table 12 - Comparison of the averages of eosinophiles (mm_) , using Tukey test with $95 \%$ of probability.

\begin{tabular}{|lll|}
\hline & LANDRACE & LARGE WHITE \\
\hline Machos & $552.96 \mathrm{Aa}$ & $534.20 \mathrm{Aa}$ \\
\hline Fêmeas & $962.44 \mathrm{Aa}$ & 891.84 Ab \\
\hline MÉDIA GERAL & 735.36 eosinófilos/mm \\
\hline
\end{tabular}
sexos.

Houve diferença significativa entre as médias de percentagens de eosinófilos $\left(\mathrm{mm}^{3}\right)$ entre os Observações: As mesmas da tabela 2.

\section{Basófilos $\left(/ \mathrm{mm}^{3}\right)$ Polimorfos nucleares - basófilos}

(\% ou número de basófilos por milímetro cúbico de sangue $=/ \mathrm{mm}^{3}$ )

Tabela 13 - Comparação das médias das porcentagens de basófilos (\%) pelo teste de Tukey em nível de 95\% de probabilidade.

Table 13 - Comparison of the averages of basophiles (\%), using Tukey test with 95\% of probability.

\begin{tabular}{|lll|}
\hline & LANDRACE & LARGE WHITE \\
\hline Machos & $1.2 \mathrm{Ab}$ & $1.48 \mathrm{Ab}$ \\
\hline Fêmeas & $2.00 \mathrm{Ab}$ & $2.00 \mathrm{Aa}$ \\
\hline MÉDIA GERAL & 1.65 por cento & \\
\hline
\end{tabular}

Houve diferença significativa entre as médias de percentagens de basófilos (\%) entre os sexos. Observações: As mesmas da tabela 2.

Tabela 14 - Comparação das médias das porcentagens de basófilos $(\mathrm{mm} \approx)$ pelo teste de Tukey em nível de $95 \%$ de probabilidade.

Table 14 - Comparison of the averages of basophiles (mm_) , using Tukey test with 95\% of probability.

\begin{tabular}{|lll|}
\hline & LANDRACE & LARGE WHITE \\
\hline Machos & $238.12 .96 \mathrm{Aa}$ & $299.88 \mathrm{Aa}$ \\
\hline Fêmeas & $367.52 \mathrm{Aa}$ & $348.32 \mathrm{Ab}$ \\
\hline MÉDIA GERAL & 313.46 basófilos/mm & \\
\hline
\end{tabular}

Não houve diferença significativa entre as médias de percentagens de basófilos $\left(\mathrm{mm}^{3}\right)$ entre os sexos e entre as raças.

Observações: As mesmas da tabela 2 


\section{Linfócitos}

(\% ou número de linfócitos por milímetro cúbico de sangue $\left.=/ \mathrm{mm}^{3}\right)$.

Tabela 15 - Comparação das médias das porcentagens de linfócitos (\%) pelo teste de Tukey em nível de $95 \%$ de probabilidade.

Table 15 - Comparison of the averages of lymphocytes (\%), using Tukey test with 95\% of probability.

\begin{tabular}{|lll|}
\hline & LANDRACE & LARGE WHITE \\
\hline Machos & $61.20 \mathrm{Aa}$ & $60.68 \mathrm{Aa}$ \\
\hline Fêmeas & $58.40 \mathrm{Aa}$ & $60.20 \mathrm{Ab}$ \\
\hline MÉDIA GERAL & 60.12 por cento & \\
\hline
\end{tabular}

Não houve diferença significativa entre as médias de percentagens de linfócitos (\%) entre os sexos. Observações: As mesmas da tabela 2.

\section{Linfócitos $\left(/ \mathrm{mm}^{3}\right)$}

Tabela 16 - Comparação das médias dos números absolutos de linfócitos $(\mathrm{mm} \approx)$ pelo teste de Tukey em nível de $95 \%$ de probabilidade.

Table 16 - Comparison of the averages of lymphocytes (m__) , using Tukey test with $95 \%$ of probability.

\begin{tabular}{|lll|}
\hline & LANDRACE & LARGE WHITE \\
\hline Machos & $12.913,20 \mathrm{Aa}$ & $12.568,30 \mathrm{Aa}$ \\
\hline Fêmeas & $10.852,20 \mathrm{Aa}$ & $10.342,00 \mathrm{Aa}$ \\
\hline MÉDIA GERAL & $11.669,062 \mathrm{~mm}_{-}$de sangue \\
\hline
\end{tabular}

Houve diferença significativa entre as médias de percentagens de linfócitos $\left(\mathrm{mm}^{3}\right)$ entre os sexos. Observações: As mesmas da tabela 2.

\section{- Monócitos}

( $\%$ ou número de monócitos por milímetro cúbico de sangue $=/ \mathrm{mm}^{3}$ ).

Tabela 17 - Comparação das médias de monócitos (\%) pelo teste de Tukey em nível de 5\% de probabilidade.

Table 17 - Comparison of the averages of monocytes (\%), using Tukey test with 95\% of probability.

\begin{tabular}{|lll|}
\hline & LANDRACE & LARGE WHITE \\
\hline Machos & $3.48 \mathrm{Ba}$ & $4.76 \mathrm{Aa}$ \\
\hline Fêmeas & $4.20 \mathrm{Ba}$ & $5.24 \mathrm{Aa}$ \\
\hline MÉDIA GERAL & 4.42 por cento & \\
\hline
\end{tabular}




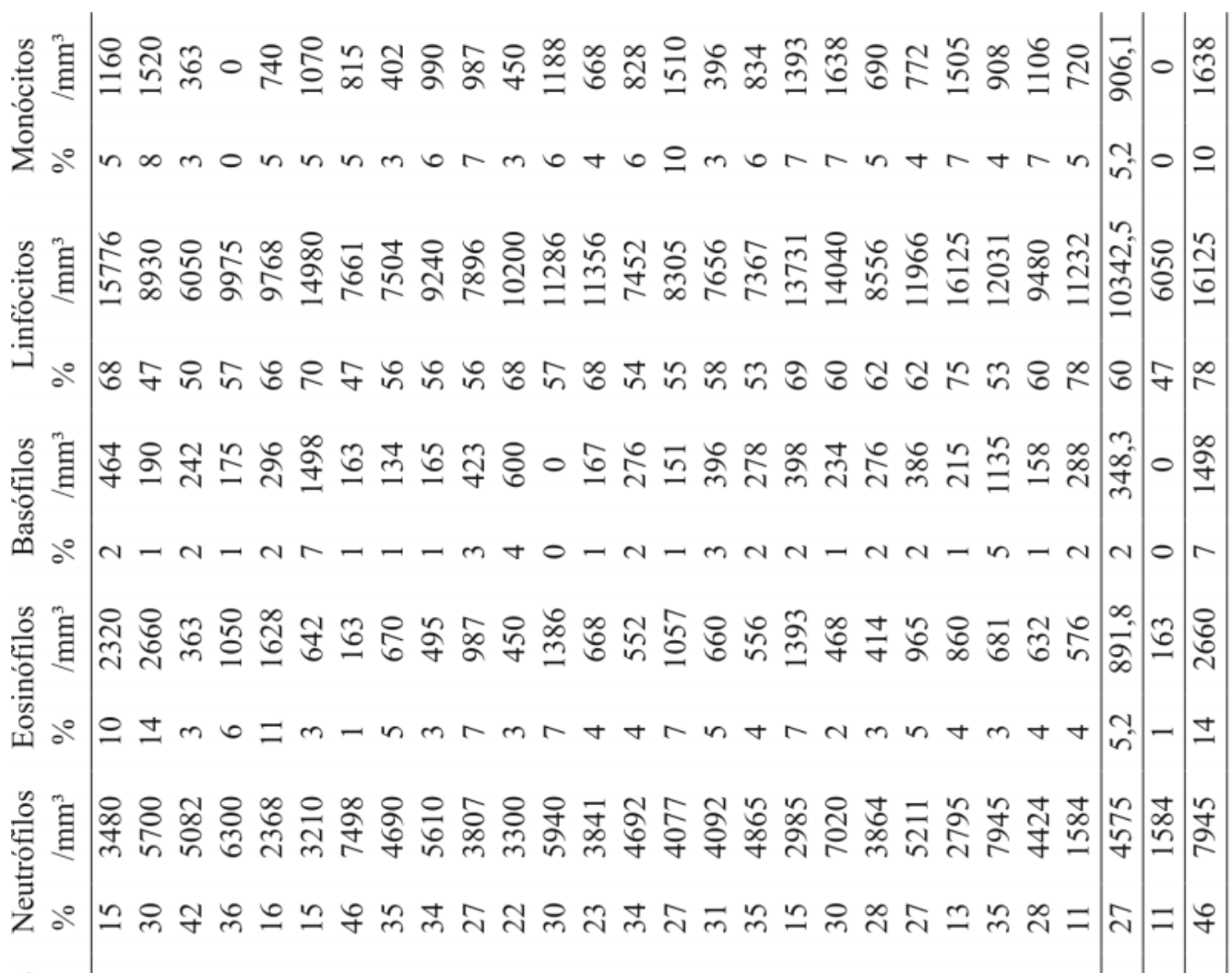

Antonia Maria do Rocio Binder do Prado

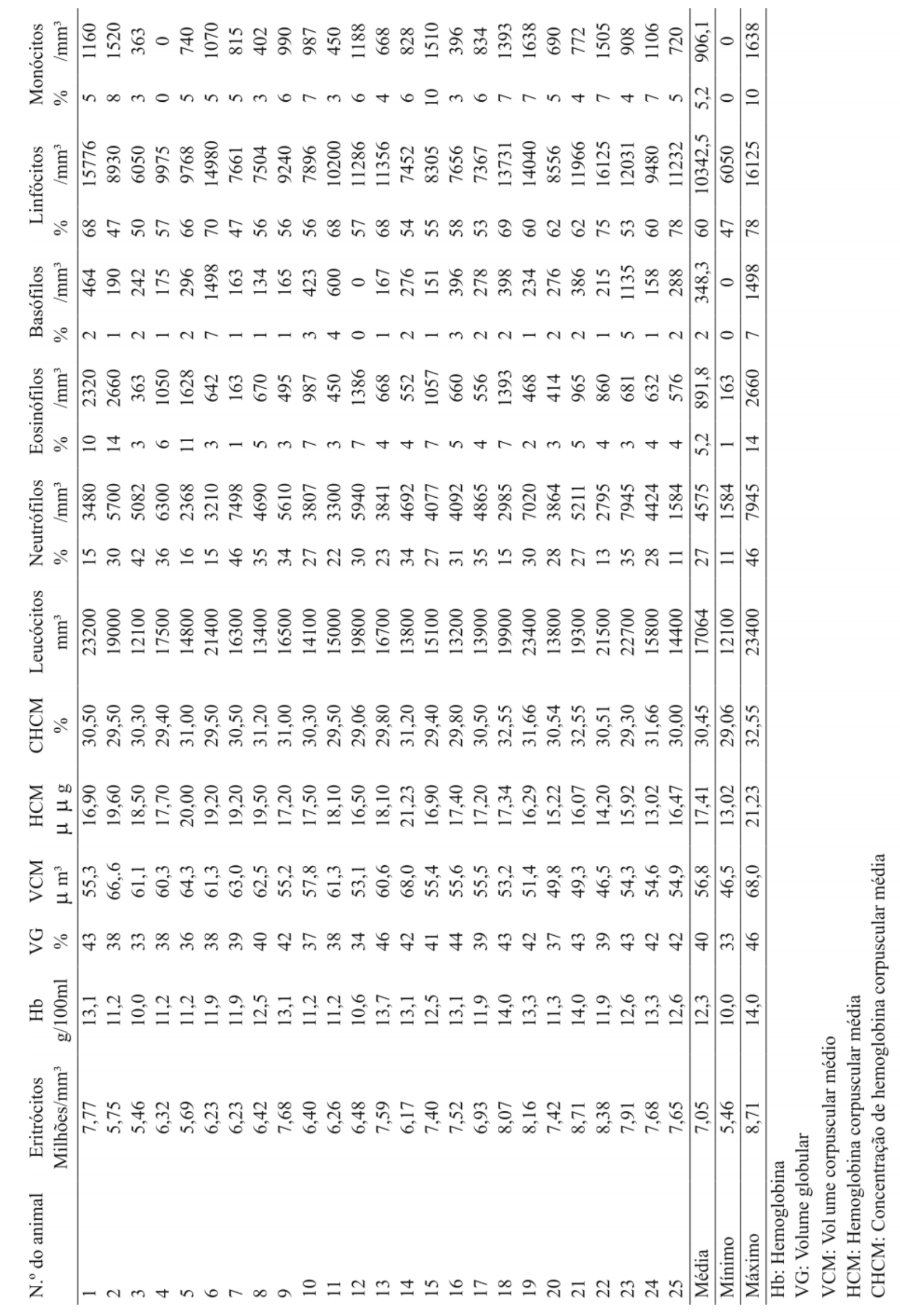




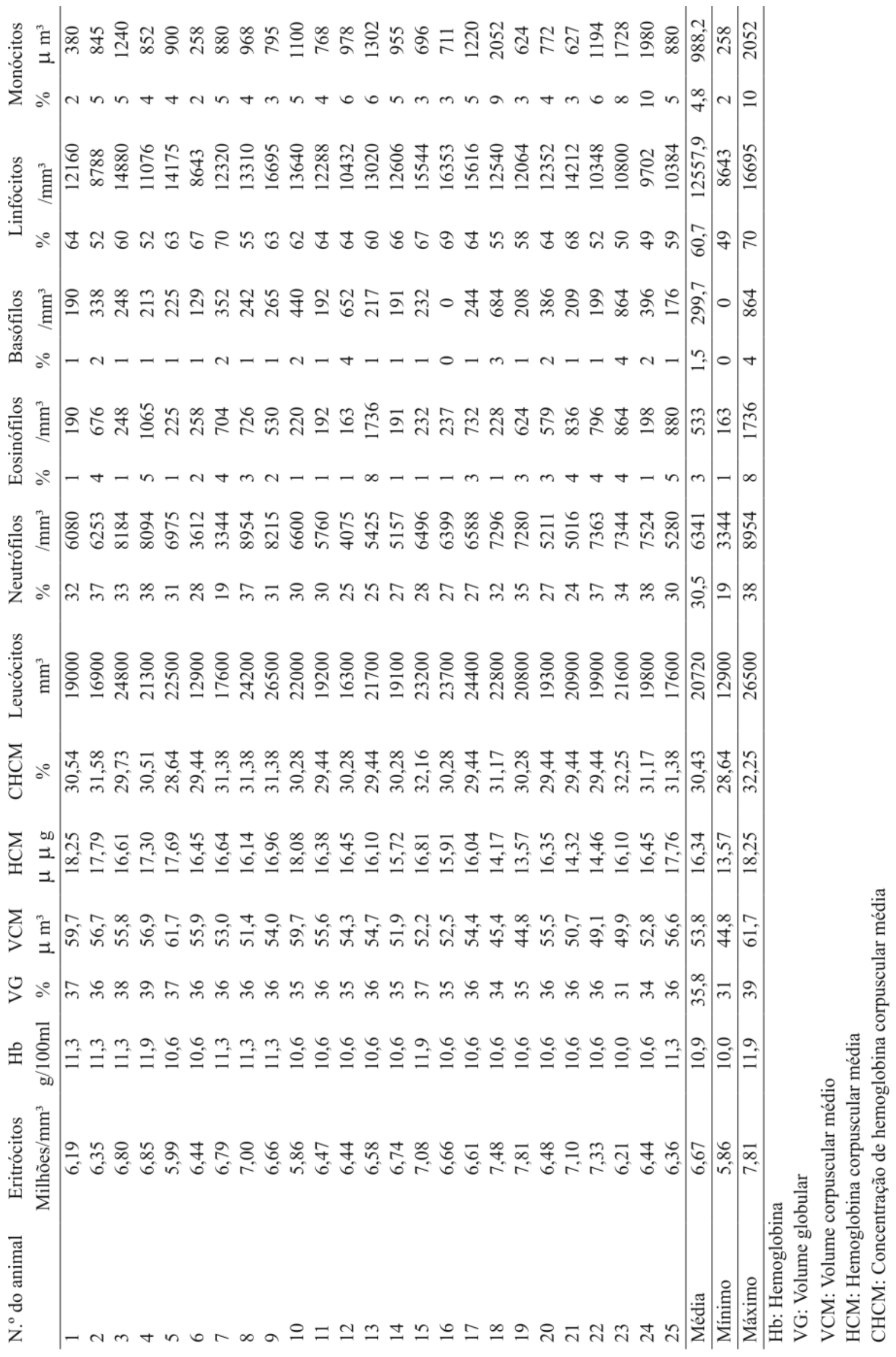




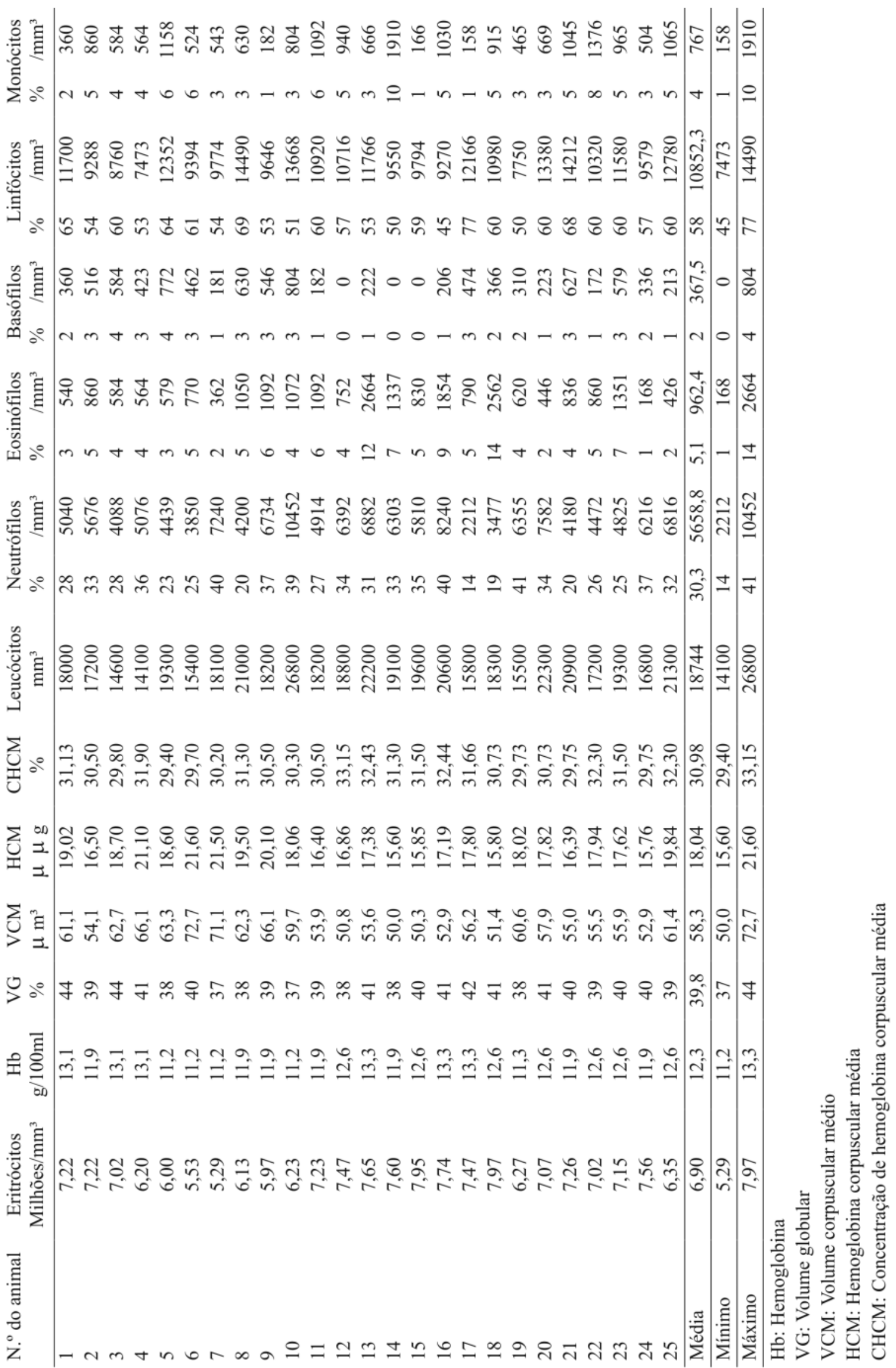




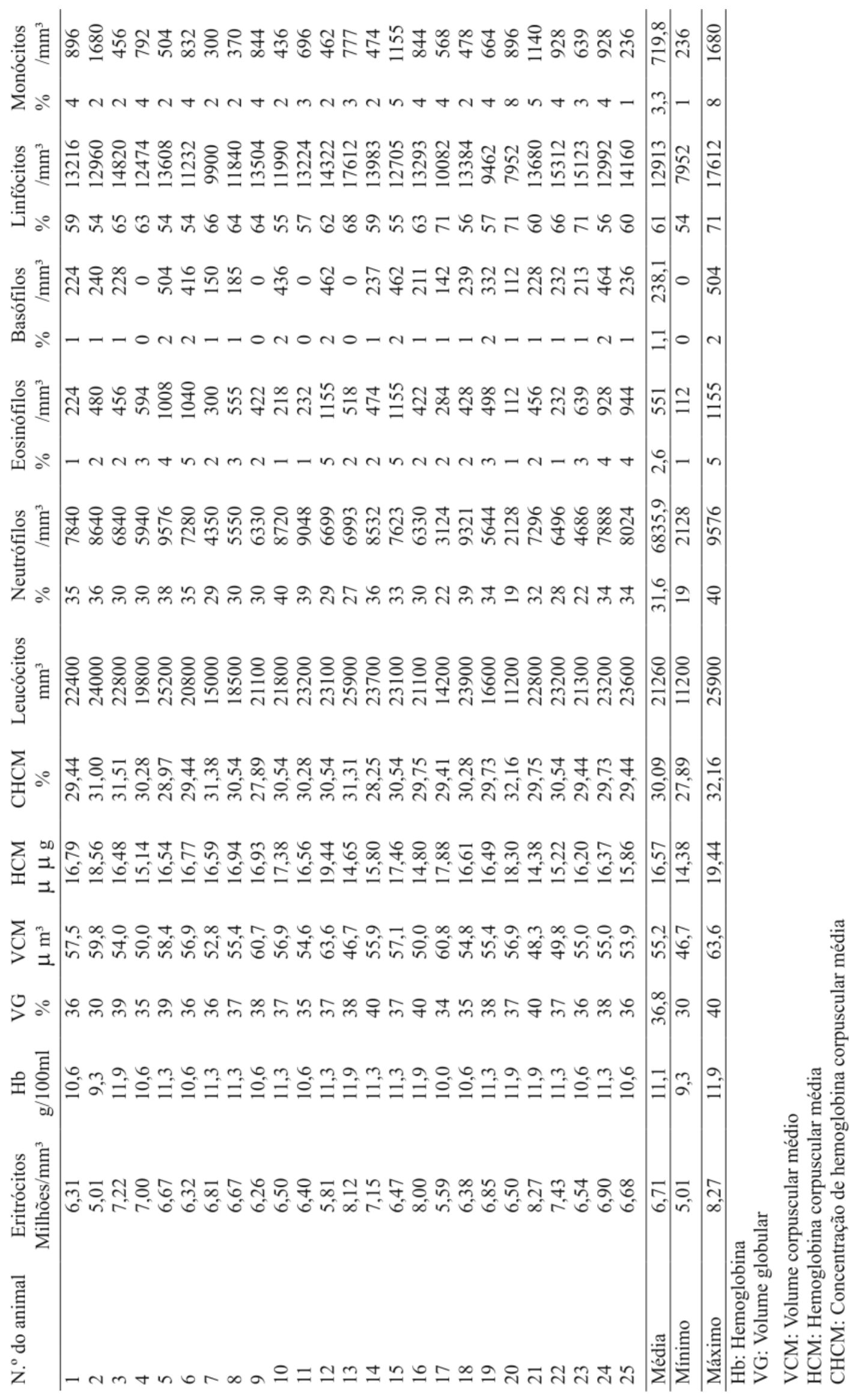




\section{Conclusões}

A análise estatística efetuada permitiu estabelecer as seguintes conclusões concernentes aos valores hematimétricos normais de suínos pertencentes às raças Landrace e Large White, a partir da análise de variância, que demonstrou, em relação aos valores supramencionados, diferenças estatísticas significantes para os sexos dentro das respectivas raças.

\section{1 - Eritrócitos}

- Média da raça Landrace: $6.808,80 / \mathrm{mm}^{3}$.

- Média da raça Large White: 6.860,00/ $\mathrm{mm}^{3}$.

- Média geral para as duas raças: 6.834,00/ $\mathrm{mm}^{3}$.

- Não houve diferença significante entre as médias das raças e dos sexos.

\section{2 - Hemoglobina.}

- Média da raça Landrace: 11,68 g/l00 ml.

- Média da raça Large White: 11,57 g/100 $\mathrm{ml}$.

- Média geral para as duas raças: 11,62 g/ $100 \mathrm{ml}$.

- Não houve diferença significante entre as médias das raças, mas existem entre as médias dos sexos.

\section{3 - Volume globular}

- Média da raça Landrace: 38,30\%.

- Média da raça Large White: 37,86\%.

- Média geral para as duas raças: 38,08\%.

- Não houve diferença entre as raças, porém existe entre as médias dos sexos.

\section{4 - Volume corpuscular (VCM)}

- Média da raça Landrace: 56,79 $\mathrm{pm}^{3}$.

- Média da raça Large White: 55,52 $\mathrm{pm}^{3}$.

- Média geral para as duas raças: 56,14 pm³.

- Houve diferença entre as médias dos sexos para cada uma das raças, porém para as raças não houve diferença ao se considerar o sexo.

\section{5 - Hemoglobina corpuscular média (HCM)}

- Média da raça Landrace: 17,30 uug.

- Média da raça Large White: 16,88 uug.

- Média geral para as duas raças: 17,00 uug.

- Houve diferença entre as médias dos sexos e não entre as das raças.
6 - Concentração de hemoglobina média (CHCM)

- Média da raça Landrace: 30,53\%.

- Média da raça Large White: 30,44\%.

- Média geral para as duas raças: 30,49\%.

- Houve diferença entre as médias para as categorias da raça Landrace, enquanto para a raça Large White essas diferenças não existiram.

\section{7 - Leucócitos}

- Média da raça Landrace: $19.942 / \mathrm{mm}^{3}$.

- Média da raça Large White: $18.902 / \mathrm{mm}^{3}$.

- Média geral para as duas raças: 19.422/ $\mathrm{mm}^{3}$.

- Houve diferença entre os sexos, não entre as raças.

\section{8 - Neutrófilos $\left(/ \mathrm{mm}^{3}\right)$}

- Média da raça Landrace: $6.247 / \mathrm{mm}^{3}$.

- Média da raça Large White: $5.46 \mathrm{l} / \mathrm{mm}^{3}$.

- Média geral para as duas raças: 5.854/ $\mathrm{mm}^{3}$.

- Houve diferença entre as médias das raças e entre as médias dos sexos.

\section{9 - Neutrófilos (\%)}

- Média da raça Landrace: 30,96\%.

- Média da raça Large White: 28,94\%.

- Média geral para as duas raças: 29,95\%.

- Não houve diferença das médias para as raças e para os sexos.

\section{0 - Eosinófilos $(\mathrm{mm} \approx)$}

- Média da raça Landrace: $757 / \mathrm{mm}^{3}$.

- Média da raça Large White: $713 / \mathrm{mm}^{3}$.

- Média geral para as duas raças: $735 / \mathrm{mm}^{3}$.

- Houve diferença entre as médias dos sexos.

\section{1 - Eosinófilos (\%)}

- Média da raça Landrace: 59,80\%.

- Média da raça Large White: 60,44\%. Média geral para as duas raças: 60,12\%.

- Houve diferença entre as médias dos sexos

12 - Basófilo $\left(/ \mathrm{mm}^{3}\right)$ -

- Média da raça Landrace: 302/ $\mathrm{mm}^{3}$.

- Média da raça Large White: $324 / \mathrm{mm}^{3}$. 
- Média geral para as duas raças: $313 / \mathrm{mm}^{3}$.

- Não houve diferença entre as médias das raças e dos sexos.

\section{3 - Basófilo (\%)}

- Média da raça Landrace: 1,56\%.

- Média da raça Large White: 1,74\%. Média geral para as duas raças: 1,65\%.

- Houve diferença entre as médias dos sexos.

\section{4 - Linfócito $\left(/ \mathrm{mm}^{3}\right)$}

- Média da raça Landrace: $11.882 / \mathrm{mm}^{3}$.

- Média da raça Large White: $11.455 / \mathrm{mm}^{3}$.

- Média geral para as duas raças: 11.669/ $\mathrm{mm}^{3}$.

- Houve diferença entre as médias dos sexos.

\section{5 - Linfócitos (\%)}

- Média da raça Landrace: 59,80\%.

- Média da raça Large White: 60,44\%.

- Média geral para as duas raças: 60,12\%.

- Não houve diferença entre as médias dos sexos e das raças.

16 - Monócitos $(\mathrm{mm} \approx)$

- Média da raça Landrace: $75 \mathrm{~mm} \approx$

- Média da raça Large White: $94775 \mathrm{~mm} \approx$

- Média geral para as duas raças: $84975 \mathrm{~mm} \approx$

- Houve diferença entre as médias das raças.

\section{7 - Monócitos (\%)}

- Média da raça Landrace: 3,84\%

- Média da raça Large White: 5,00\%

- Média geral para as duas raças: 4,42\%.

- Houve diferença entre as médias das raças.

\section{Referências}

THE VOLUME and hemoglobin content of red blood corpuscle. AMERJ Med Sci. Philadelphia, p.177 - 513, 1929.

COFFIN, D.L. Laboratório Clínico em Medicina Veterinária. 3. ed. México: La Prensa Médica Mexicana, 1959. p. 335.
COLES, H. E. Veterinary clinical pathology. 2. ed. V.B. Philadelphia: Saunders, 1974. p. 42 - 44; $105-115$.

CRAFT, W. A.; MOE, L.H. Statistical observations involving weight hemoglobin and the proportion of white blood cells in pigs. J Am Vet Med Ass. v. 34, p. 405-7, 1932.

DUKES, H. H. Fisiologia de los animales domésticos. 7. ed. Madrid: Aguilar, 1960. p. 962.

FERREIRA NETO, J. M. Hemograma de suínos da raça York-shire do nascimento aos 15 meses de idade. Arq Ex Vet Univ Fed. Minas Gerais, v. 31 , n. 2, p. 125-32,1979.

FREITAS, OT. Hemotocitologia de Didelphis azarae. Curitiba, 1967. 59 f. Tese (Livre Docência), Universidade Federal do Paraná. Curitiba, 1967.

GARDINER, M. R.; SIPPEL, W. L.; MC CORMICK, W. C. The blood picture in newborn pigs. Am J Vet Res. v.14, p. 68-71, 1953.

GILTNER, Ward. The histology and physiology of normal pigs blood. J Vet Res. v. 14, p. 68-71, 1953.

GORDON, H. Mcl.; WITLOCK, H. V. A new technique for counting nematods eggs in sheep faeces. J Counc Sci Ind Res. Aust. v. 12, p. 502, 1939/1940.

LUKE, D. The differential leukocyte count in the normal pig. J. Comp. Pathol.Ther. v. 63, p. 34654, 1953.

MATOS, M. S. et al. Hemograma de suínos clinicamente sadios; influência de idade e sex o. Arq Esc Med Vet Univ Fed. Bahia, v. 3, n. 1, p. 52-62, 1978.

PALMER, C. C. Morphology of normal pigs blood. J Agr Res. v. 9, p. 131, 1917.

SCARBOROUGH, R A. The blood picture of normal laboratory animals. Yale $\mathbf{J}$ of Biol and Med. v. 3, p. 547-52, 1931.

SCHALM, OW. ; JAIN, N. C.; CARROL, E. J. Veterinary hematology. 3. ed. Philadephia: Loa and Febiger, 1975. p. 807.

STTEL, R. G. D.; TORRIE, H. H. Priciples and procedures of statistics. New York: McGrawHill, 1960. 
SWENSON, M .J. La sangre; propriedades fisiológicasy constituyentes celulares y químicos. In: DUKES, H. H.; SWENSON, M. J. Fisiologia de los animales domésticos. México: Aguilar, 1970. v. l, p. 27-77.

VEEN, J. A J. Variations in the leukocyte count of the pig during the first twelve weeks of life. J. Comp.

Pathol. v. 54, p. 172, 1944.
WILWERTH, A M.; COSTAVAL, V. P.; BARBOSA, M. $\mathrm{O}$ quadro hematológico dos suínos. Arq Esc Vet URE. Minas Gerais v. 3, p. 67-71, 1950.

WINTROBE, M. M. Clinical hematology. 4.ed. Philadelphia: Loa \& Febiger, 1967. p. 1185.

Recebido 15/02/2003

Aprovado 30/01/2004 